\title{
Testing an Inference of Function From Structure: Snake Vertebrae Do the Twist
}

BRAD R. MOON*

Department of Biology, The University of Michigan, Ann Arbor, Michigan

ABSTRACT The zygapophyses and zygosphene-zygantrum articulations of snake vertebrae are hypothesized to restrict or el iminate vertebral torsion. This hypothesis is apparently based solely on the inference of function from structure, despite the limitations of such inferences, as well as contradictory observations and measurements. In this study, I observed and measured axial torsion in gopher snakes, Pituophis melanol eucus. To exami ne the structural basis of axial torsion, I measured the vertebral articulation angles along the body and the insertion angles of five epaxial muscles. To examine torsion in a natural behavior, I digitized video images and measured the degree of apparent axial torsion during terrestrial lateral undulation. Finally, I measured the mechanical capacity of the vertebral joints for actual torsion over intervals of 10 vertebrae in fresh, skinned segments of the trunk. Vertebral articulation angles vary up to $30^{\circ}$ and are associated with variation in torsional capacity al ong the trunk. The freely crawling P. melanol eucus twisted up to $2.19^{\circ}$ per vertebra, which produced substantial overall torsi on when added over several vertebrae. The vertebral joints are mechanically capable of torsion up to $2.89^{\circ}$ per joint. Therefore, despite the mechanical restriction imposed by the complex articulations, vertebral torsion occurs in snakes and appears to be functionally important in several natural behaviors. Even in cases in which mechanical function appears to be narrowly constrained by morphology, specific functions should not be inferred solely from structural analyses. J . Morphol. 241:217-225, 1999. @ 1999 Wiley-Liss, Inc.

KEY WORDS: snake; vertebrae; osteology; morphology; functional morphology; torsion; gopher snake; Pituophis; biomechanics; anatomy

Understanding the relationship between organismal structure and function is a fundamental goal of morphology and biology in general. In many cases in which the functions of particular structures are not easily (or cannot be) observed, mechanical analyses and modeling have been very productive in supporting functional inferences (e.g., Rudwick, '64; Wainwright et al., '76; Kingsolver and Koehl, '85; Thomason and Russell, '86; Wei shampel, '93). Yet in other cases, especially seemingly obvious ones in which function appears to be narrowly constrained by structure, functions are assumed but not directly tested. However, biological structures and their functions generally havecomplex relationships with one another that rarely, if ever, support specific functional inferences (Gans and Gasc, '92; Lauder, '95). Vertebral torsion in snakes provides a case study in which a reasonable, long-standing functional inference from structure is not supported by experimental testing.

Snakes are unusual among vertebrates in having five points of articulation between adjacent vertebrae (Romer, '56; Hoffstetter and Gasc, '69). Three of these, at each centrum and left and right zygapophysis, represent ancestral features of vertebrates. The two additional articulations, between the left and right zygosphenes and zygantra, are unique to some squamate reptiles and are most highly developed in snakes (Hoffstetter and Gasc, '69). In an early study, Mosauer ('32) observed that the zygapophyses and

*Correspondenceto: Brad Moon, Department of Radiology, Box 357115, University of Washington Medical Center, Seattle WA 98195-7115. E-mail: bmoon@u.washington.edu 
zygosphene-zygantrum articulations oppose one another, and concluded that this architecture makes torsion at the vertebral joints "wholly impossible." Similarly, more recent reviews have assumed that thezygosphenezygantrum articulations prevent, or at least minimize, vertebral torsion (e.g., Gans, '74; Edwards, '85; Cundall, '87). Nevertheless, this functional inference was based solely on extrapolation from structure.

Gasc ('74, '76) was the first to measure actual torsion of $1-2^{\circ}$ between adjacent vertebrae in dried Python skeletons, but he argued that torsion would be restricted further in living snakes by the articular cartilages and ligaments. Cundall ('87) stated that this level of torsion is negligible, and therefore presumably functionally unimportant. However, although $1-2^{\circ}$ of twisting may be negligible for a single joint, overall torsion can become substantial when added over many vertebrae used in axial bending movements. For example, snakes have 120 to over 350 vertebrae (H offstetter and Gasc, '69), and often use 20-100 of these in a single axial bend during locomotion ( ayne, '88a; Moon and Gans, '98).

Several published observations also suggest that vertebral torsion occurs in snakes. For example, axial twisting movements occur during locomotion (Gans and Mendelssohn, '72; Gasc, '74; Moon and Gans, '98), prey capture and feeding (Frazzetta, '66; Greene and Burghardt, '78; J anoo and Gasc, '92), and defense (Fitch, '63). However, the appearance of axial torsion can be produced by three nonexclusive mechanisms: differential abduction of the left and right body walls, which in dorsal view gives the appearance of rotation about the long axis, combined lateral and vertical bending (Gans and Mendel ssohn, '72; Gans, '74), and actual torsion at the vertebral joints (Gasc, '74, '76). Therefore, it is important to distinguish between apparent axial torsion, which may involve the multiple mechanisms noted above, and vertebral torsion that occurs at the intervertebral joints.

In a series of studies on the functional morphology of snakes (M oon, '98), I observed axial torsion during terrestrial lateral undulation, prey capture, and constriction in gopher snakes (Pituophis melanol eucus). These observations suggested that gopher snakes may indeed be capable of measurable vertebral torsion. Therefore, to test the traditional hypothesis that snake vertebral articu-
Iations prevent torsion, I observed and measured the morphological, kinematic, and mechanical bases of the apparent axial torsion. Theresults document substantial variation in vertebral structure and function al ong the body, and indicate that even when morphology narrowly constrains mechanical function, inferences of function solely from structural analysis must be tested empirically.

\section{MATERIALS AND METHODS Specimens}

For this study, I used specimens of Pituophis mel anol eucus affinis (Pma) from southern Arizona, P. m. deserticola (Pmd) from Idaho, and P. m. sayi (Pms) from Montana. Although P. melanoleucus is geographically widespread and variable in external morphology, vertebral morphology was similar among indi viduals from the different subspecies, so the specimens were combined in the analyses.

\section{Vertebral morphology}

To examine the vertebral articulations, I digitized video images of every tenth vertebrae from four skeletons (two Pmd and two Pms) that were cleaned by beetle larvae. I then used Measurement TV (DataCrunch Software) to measure the angles between the left and right articular facets of the zygosphenes and prezygapophyses (Fig. 1).

\section{Epaxial muscleanatomy}

The epaxial muscles of snakes are hypothesized to be important axial flexors (Gasc, '74; Ruben, '77; Gasc, '81). Some of these muscles insert at oblique angles and therefore are mechanically suited to producing torsional movements. I measured the insertion angles for five epaxial muscles, the $\mathrm{Mm}$. iliocostal is, longissi mus dorsi, multifidis, and both parts of the spinalis-semispinalis ( $\mathrm{N}=$ 1 Pma). Specifically, I determined the approximate vertical insertion angle of each muscle trigonometrically based on muscletendon length and change in height between insertions. The insertion angles also have horizontal components (Gasc, '74, '76) but these were not measured. The epaxial muscular anatomy of snakes has been described in several accounts (Pregill, '77; Gasc, '81; J ayne, '82; Moon and Gans, '98). Therefore, herein I only briefly summarize the gross muscular anatomy of gopher snakes. 
A

Fig. 1. A: Anterior view of vertebra 190 of Pituophis melanoleucus. B: Thearticulation angles measured in this study. C: The centers of rotation of the centrum (C), pre- and postzygapophysis $(P)$, and zygosphene-zygantrum (Z) articulations.

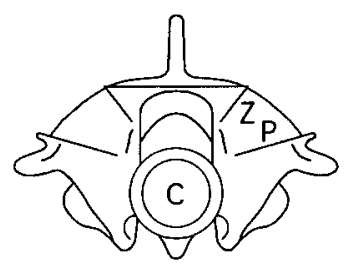

B

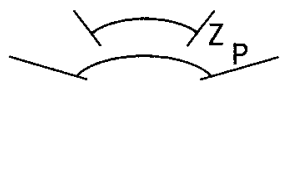

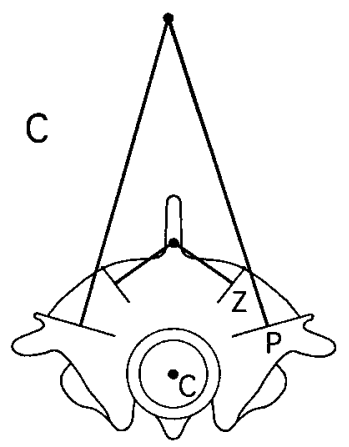

\section{Apparent locomotor torsion}

To measure the apparent axial torsion during locomotion, I digitized macro dorsal video images of terrestrial lateral undulation in threegopher snakes (Pma) that were painted with a white stripe along the vertebral midline and a white crossbar at every tenth vertebra. The mid-dorsal skin of most snakes (e.g., Lissmann, '49; J ayne, '88b), including gopher snakes (Pregill, '77), is tightly connected to the neural spines by thick connective tissue that prevents the skin from sliding relative to the vertebral midline. In gopher snakes, the connection of the middorsal skin to the neural spines is so strong that it is difficult to removetheskin from the midline during dissection; in living snakes, the skin cannot be pulled laterally from the vertebral midline by hand or with toothed forceps. Therefore, the painted midlinestripe is an acceptable landmark for measuring apparent axial twisting.

The video images recorded the snakes crawling on a smooth, painted plywood board and pushing against a single plastic peg that projected from the center of the board. F rom these video images, I used Measurement TV to measure the position of the vertebral midline relative to the left and right body walls over lengths of 10 vertebrae in the bend immediately posterior to the point of contact with the peg. Measurements were restricted to the trunk between vertebrae 80 and 130 , where the width of the body was uniform. I used a computer spreadsheet to calculate apparent torsion using the relation $\mathrm{T}=$ arcsine $(\mathrm{d} / \mathrm{r}) *(180 / \pi)$, where $\mathrm{T}=$ torsion, $\mathrm{d}=$ lateral displacement (in dorsal view) of the vertebral midline relative to the body walls over intervals of 10 vertebrae, $r=$ theradius of the snake trunk, and $180 / \pi$ converts the valuefrom radians to degrees. I then divided the value by 10 to calculate the torsion per vertebral joint.

Two potential sources or error may complicate these measurements. The cal culation of three-dimensional torsion from two-dimensional video images is prone to large error at rotational displacements beyond ca. $30-45^{\circ}$ because the amount of lateral displacement per unit of twisting decreases in the twodimensional dorsal view as rotation increases. Nevertheless, the measurements should be accurate over the limited rotations (up to ca. $20^{\circ}$ over 10 vertebrae) exhibited by gopher snakes. In addition, abduction of the ribs and body wall on one side combined with their adduction on the other side would give the appearance in dorsal view of the vertebral midline twisting toward one side in the absence of real twisting. To evaluate the contributions of such move ments, as well as of lifting, I made close-up visual observations during all video recordings. Differential movement of the ribs and body wall occurred immediately anterior to the peg, but appeared to be absent from the trunk posterior to the peg, where axial torsion was measured. Therefore, the twodimensional video measurements provide valid, but preliminary, estimates of axial torsion. I present these data to supplement published observations (see Discussion) indicating that vertebral torsion occurs during natural behaviors. More rigorous threedimensional methods are needed to make more precise measurements of vertebral torsion in freely moving snakes.

\section{Vertebral capacity for torsion}

To measure the capacity of gopher snake vertebrae for actual torsion, I prepared fresh, skinned segments of the body including 20-30 vertebrae from six specimens (four 
A

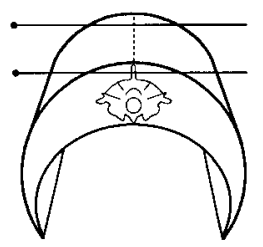

B

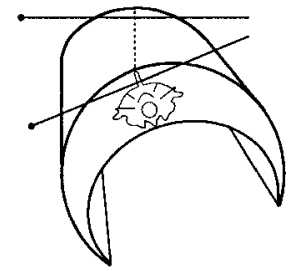

C

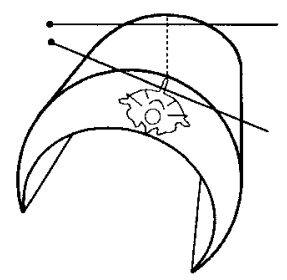

Fig. 2. Method for measuring the capacity for vertebral torsion. A: Method of inserting pins horizontally through the dorsal tissues between the neural spines. B,C: The section of 10 vertebra was twisted maximally toward the left and then the right without inducing any

Pmd and two Pma). I clamped each segment at one end, then placed a dissecting pin horizontally through the specimen at the clamped end and at the tenth vertebra from the first pin. I then twisted the free end by hand, digitized video images of maximal left and right rotations (which allowed me to control for differences in starting angle), and measured the angles between the pins at each rotational limit (Fig. 2). The video camera was mounted horizontally and the specimen held horizontally so that its long axis was perpendicular to the video camera. The limits of twisting were clearly detectable and were reached before the movement produced any axial bending. I divided the total rotation by two to calculate the capacity for torsion in one direction, and then divided the value by 10 to calculate the torsion allowed at each vertebral joint. To test for a significant difference in torsion between vertebra 10 and all further posterior vertebrae, I used a one-sample t-test and a significance level of $\alpha=0.05$

RESULTS

\section{Vertebral morphology}

The pre- and postzygapophyses are situated at the upper limit of the centrum and the base of the neural arch. The angle between left and right prezygapophyses in these gopher snakes varies from 154.4$184.8^{\circ}$ along the trunk (mean \pm SD $=$ $161.14 \pm 7.04, \mathrm{~N}=4$; Fig. 3). In the first 10-20 vertebrae, the zygapophyses are very small and nearly horizontal; because the articular angles are slightly greater than 180 in these vertebrae, the facets face dorsolaterally and the centers of rotation are below the articular facets. The articular facets are most inclined in the midtrunk, then be- axial bending. The anterior end of each 10 vertebra section (the end facing into the page, away from the reader) was immobilized in a clamp (not shown). The maximal rotations were digitized and thetorsional capacity measured as described in Materials and Methods.

come more horizontal again toward the tail (F ig. 3). Therefore, the zygapophyseal angles of the midtrunk are the most steeply inclined and have centers of rotation well above the vertebrae (Fig. 1).

The zygosphene-zygantrum articulation occurs at the dorsolateral limits of the neural canal, just below the base of the neural spine. Themean angle between left and right zygosphenes varies slightly along the trunk from 63.4- 79. $7^{\circ}$ (mean $\pm S D=73.6 \pm 3.73$, $\mathrm{N}=4 ;$ Fig. 3). The centers of rotation of these articulations are well above centra along the entire trunk (Fig. 1). As in the zygapophyseal articulations, the indination of the zygospheneal articular facets is least in the neck and greater posteriorly (Fig. 3). Thezygospheneal and zygapophyseal articulations are oriented $45.5-52.6^{\circ}$ from one another.

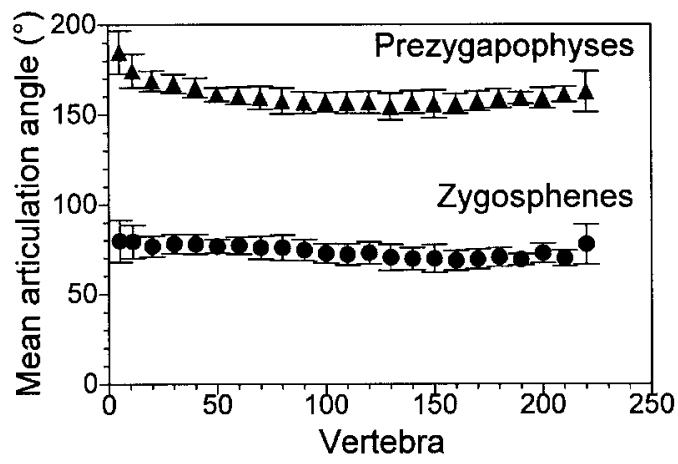

Fig. 3. Mean $\pm \mathrm{SD}$ angles ( $\mathrm{N}=4$ specimens) be tween left and right articular facets of the prezygapophyses and zygosphenes along the trunk of Pituophis melanoleucus. 
Epaxial muscleanatomy

Several of the axial muscles insert on the vertebrae at oblique angles and thus are mechanically suited to producing both lateral bending and torsional movements. All of the angles reported here are for the vertical plane and are relative to the long axis of the vertebral column; positive angles indicate that the muscle-tendon elements are aligned anterodorsal to posteroventral and negative angles indicate anteroventral to posterodorsal alignment. Three of the epaxial muscles interconnect via long tendons to form a compl ex muscle-tendon chain that spans 22 vertebral joints and has four insertions (Fig. 4). The M . Iongissi mus dorsi originates from the prezygapophyseal process, spans four joints, and has a bifurcating anterior tendon that is continuous ventral ly with the $\mathrm{M}$. iliocostalis and dorsally with the $\mathrm{M}$. spinalis-semispinalis. Theanteroventral tendon of the M. Iongissimus dorsi extends anteriorly for four joints at an angle of ca. $-6^{\circ}$ and is continuous with the M. iliocostalis. The M . iliocostal is spans seven joints, has an anterior tendon that extends five more joints, and inserts on a rib at an angle of ca. $-6^{\circ}$. The anterodorsal tendon of the M. Iongissimus dorsi extends four joints anteriorly at an angle of ca. $8^{\circ}$ and is continuous with the M. spinalis-semispinalis. The two parts of M. spinalis-semi spinalis have separate posterior insertions, but share a long anterior tendon and insertion. The spinalis part of the $M$. spinalis-semispinalis spans three joints and inserts posteriorly by slips onto the lateral surface of the neural spine and the tendon of the M. multifidis; the insertion angleis ca. $-15^{\circ}$. The fibers of the semispinalis part span four joints. Anteriorly, the long tendon of the M. spinal is-semi spinalis spans 10 joints and inserts on the dorsal posterior edge of a neural spine at an angle of ca. $3^{\circ}$.

Although the M. multifidis gives rise, via its posterior tendon, to a few small slips of the M. spinal is, it is otherwise separatefrom the epaxial muscle-tendon chain. The M. multifidis arises via a tendon from the posterolateral edge of a neural spine, extends anteroventrally over 2-4 vertebral joints, and inserts at an angle of ca. $-20^{\circ}$ onto the posterior surface of a postzygapophyseal process.

\section{Apparent locomotor torsion}

Gopher snakes moving by lateral undulation at speeds of 0.02 to $0.12 \mathrm{~m} / \mathrm{s}$ formed lateral bends that encompassed 22-48 vertebrae per half-wavelength. Between vertebrae 80 and 120, the lateral bends showed a mean $( \pm S D)$ apparent torsion of $0.64 \pm 0.20^{\circ}$ per vertebral joint (range $=0.02-2.19^{\circ}$ per joint, $\mathrm{N}=3$ ). The degree of apparent torsion increased when the snakes were moderately restrained, by hand, from free movement.

Close-up visual observations made during the video recordings indicated that lifting of the vertebral column did not occur, which ruled out combined lateral and vertical bending as the source of the apparent torsion. There appeared to be moderate differential abduction of the left and right body walls around the anterior surface of the peg against which the snake pushed. However,

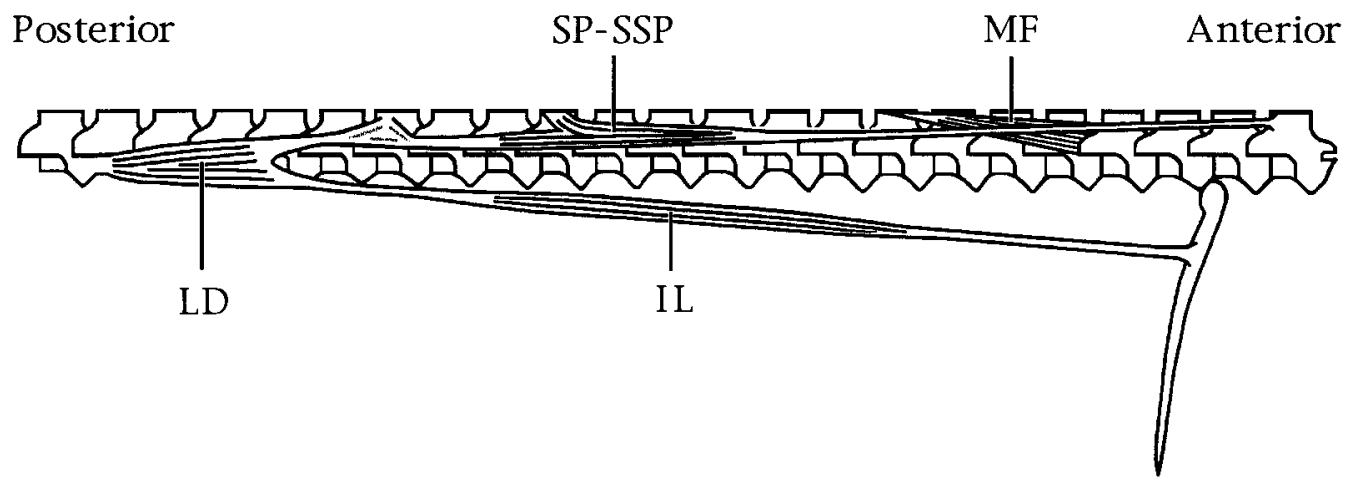

Fig. 4. Epaxial muscular anatomy of the midtrunk of the gopher snake, Pituophis melanoleucus. IL $=\mathrm{M}$. iliocostalis, $L D=M$. longissimus dorsi, $M F=M$. multifidis, SP-SSP $=$ M. spinalis-semispinalis. The oblique insertions (described in the text) suggest that these muscles can contribute to longitudinal twisting of the vertebral column. 
differential rib movements were not apparent in the trunk posterior to the peg, where theapparent torsion was measured. F urthermore, slight twisting of the trunk clearly occurred, and appeared to contribute to postural deformation around the peg.

\section{Vertebral capacity for torsion}

The trunk vertebrae allow actual torsion of 1.64-2.89 ${ }^{\circ}$ per vertebral joint (mean \pm $\left.\mathrm{SD}=1.95 \pm 0.29^{\circ} ; \mathrm{Fig} .5\right)$. This torsion was reached without inducing any axial bending; however, the amount of torsion could be increased slightly by twisting the trunk segment so far that lateral and vertical bending were forced to occur. The capacity for torsion at vertebra 10 is significantly higher than in a combined sample of the rest of the trunk vertebrae (mean $\pm S D=3.03 \pm 0.65$ vs. $1.93 \pm 0.20, \mathrm{t}_{4}=10.44, \mathrm{P}<0.001 ; \mathrm{N}=6$; Fig. 5). Torsional capacity decreases from the first 10 vertebrae posteriorly to approximately vertebra 20 , where it appears to become roughly stable throughout the rest of the trunk.

\section{DISCUSSION}

Mechanisms of torsion in natural behaviors

The axial twisting movements observed in many snakes may be produced by combined lateral and vertical bending, without any torsion at the vertebral joints (Gans and Mendelssohn, 72). F or example, axial twisting during snail extraction by Dipsas indica appears to result largely from combined lateral and vertical bending of the neck (Fig. 1 of Sazima, ‘89). Snail extraction in Storeria

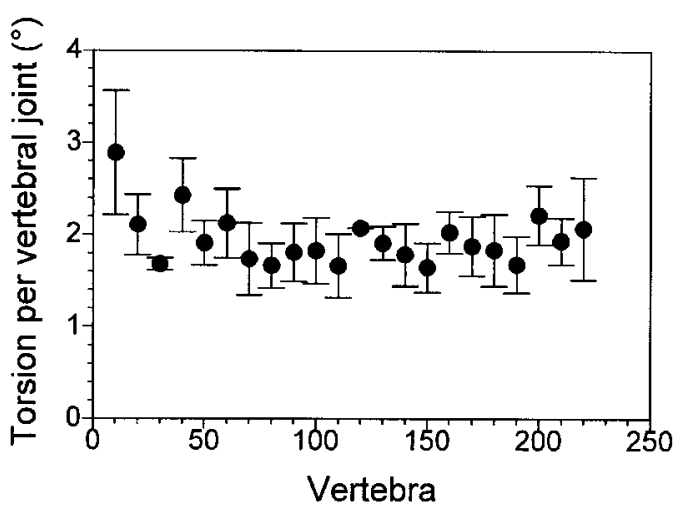

Fig. 5. Mean $\pm \mathrm{SD}$ values ( $\mathrm{N}=6$ specimens) of vertebral torsion measured in unpreserved, skinned segments of the trunk of Pituophis melanol eucus. dekayi involves cervical twisting of 180 $270^{\circ}$, which involves some lateral and vertical bending (Fig. 1 of Rossman and Myer, '90), but also suggests the contribution of vertebral torsion. The sea snake Fordonia leucobalia twists the legs off of crabs (Shine, '91), although it is unclear whether thetwisting movements involve both lateral and vertical bending movements.

In contrast to movements that involvecombined lateral and vertical bending, many twisting movements appear to involve lateral bending with little or no vertical bending; qualitative examples include terrestrial lateral undulation (Gasc et al., '89; Moon and Gans, '98), rolling over and righting during death-feigning in Heterodon species (Platt, "69), and the "initial twist" of a constriction coil (Greene and Burghardt, '78). Furthermore, many of the twisting movements exhibited by snakes often involvelittle or no axial bending. For example, twisting can approach $90^{\circ}$ in apparently strai ght sections of the neck during prey capture in some pythons (Frazzetta, '66) and vipers (J anoo and Gasc, '92). Perhaps the most pronounced and vigorous twisting movements occur in defensive or escape move ments in racers (Coluber constrictor) and whipsnakes (Masticophis species), which can twist their bodies quickly and strongly enough to sever their tails (e.g., Fitch, '63). Similarly, I have observed vigorous twisting in freshly captured Masticophis bilineatus while I intentionally held them straight, which suggests that the twisting movements can occur without lateral or vertical bending. All of these descriptions of twisting movements were brief and based on qualitative observations; quantitative studies are clearly needed for better documentation of twisting movements in snakes. Neverthe less, some of these observations, particularly of twisting movements that occur with little or no axial bending, strongly indicate the occurrence of vertebral torsion in natural behaviors.

Although apparent torsion may be produced by several mechanisms, my close-up observations of crawling gopher snakes revealed that at slow to moderate locomotor speeds, lifting of the trunk is negligible, which rules out combined lateral and vertical bending as the source of the apparent torsion. Furthermore, if the axial torsion apparent in dorsal view results solely from differential movement of the body walls, then 
close-up observations should reveal that the vertebral midline does not twist along its axis. Although differential abduction of the left and right body walls appears to occur in parts of some axial bends, actual twisting of the vertebral midline is also visible.

Several of the axial muscles insert on the vertebrae at angles and therefore are mechanically suited to producing torsional movements. However, the forms of the vertebral articulations, particularly the opposing zygospheneal and zygapophyseal articular facets and their noncoincident centers of rotation (Fig. 1), indicate that the articulations do severely restrict torsion at the vertebral joints. Nevertheless, these articulations allow $1.64-2.89^{\circ}$ of torsion per vertebral joint, which is sufficient to produce the maximum torsion of $21.9^{\circ}$ over the 10 vertebrae that I observed in crawling snakes. This range of torsion in gopher snakes is consistent with the torsion of $1-2^{\circ}$ per vertebra recorded by Gasc ('74, '76) in Python skeletons. F urthermore, because many kinds of movements in snakes invol ve large numbers of vertebrae (Gasc, '74; J ayne, '88a; Gasc et al., '89; Moon, '98; Moon and Gans, '98), even this slight torsion per joint can become substantial when added over the many vertebrae used in snake movements.

It is important to note that the measurements reported here for skinned, fresh material indicate the maximal capacity of Pituophis melanol eucus vertebrae for torsion, not the degree to which they actually twist in various natural movements. Snakes probably only rarely use their full capacity for vertebral torsion, such as for vigorous antipredator movements.

\section{Anatomical basis of torsion}

The largest capacity for torsion occurs in the anteriormost 10-15 vertebrae (Fig. 5), and appears to be related to the very small zygospheneal and zygapophyseal articular facets, and the nearly horizontal orientation of the zygapophyses. This Iarge capacity for torsion in the neck is consistent with published observations of substantial twisting in the neck of snakes during prey capture (F razzetta, '66; J anooand Gasc, '92). Posteriorly, the angles of the zygapophyses increase by as much as $30^{\circ}$, concomitant with a lower capacity for torsion than in the first 10 vertebrae.

\section{Longitudinal variation in vertebral} morphology

Longitudinal variation in vertebral morphology has been reported in both fossil (Rage and Albino, '89; LaDuke, '91) and living snakes (J ohnson, '55; Hoffstetter and Gayrard, '65; H offstetter and Gasc, '69; Gasc, '74, '76). However, systematic variation in vertebral articulation angles is not well known. In addition to having potential functional consequences, the substantial variation in zygospheneal and zygapophyseal angles along the trunk suggests that the systematic utility of these characters is less than commonly assumed (e.g., Holman, '95, p. 98). The occurrence of zygapophyseal angles greater than $180^{\circ}$ (i.e., laterally oriented facets) only in the first 10 vertebrae calls into question both the inferred longitudinal position of isolated fossil snake vertebrae and the reliability of these angles for identifying fossil taxa. For example, each of the fossil taxa Russellophis, Dolniceophis, and Elaphe nebraskensis is known from a single vertebra that is inferred to be from the midtrunk but has laterally oriented zygapophyses (Rage, '84), which are characteristic only of the 10-15 most anterior vertebrae in gopher snakes. If vertebral morphology in other snakes parallels thelongitudinal variation observed in gopher snakes, then it is possible that these fossil vertebrae are from the anterior trunk, and may not represent distinct taxa. Intracolumnar variation in vertebral morphology of the older fossil snake Dinilysia patagonica appears to be consistent with that of gopher snakes (Rage and Albino, '89), which gives some support to this conclusion and suggests that intracolumnar variation in articular morphology occurred in ancestral snakes. Clearly, Iongitudinal variation in snake morphology needs to be accounted for in functional, paleontological, and systematic studies.

\section{I nferring vs. testing function}

Biologists havelong inferred function from form (Russell, '16). However, biological structures and their functions generally havecomplex relationships with one another that rarely support specific functional inferences based solely on structural analyses (Gans and Gasc, '92; Lauder, '95). Such complex structure-function relationships occur for several reasons. For example, individual structures usually support multiple functions (e.g., Garland and Huey, '87; Dudley 
and Gans, '91; Moon, '98); multiple structures, such as muscles and bones, can be required to control a single function (e.g., Reilly and Lauder, '89; Nishikawa et al., '92; Nishikawa and Gans, '96); functional differences can occur without structural differences (e.g., Kingsolver and Koehl, '85; Sanford and Lauder, '89); and structural differences can occur without functional differences (Lauder and Shaffer, '88). Furthermore, structure-function relationships often vary in different environments (e.g., Lauder and Shaffer, '88; F rolich and Biewener, '92).

Despite these complexities, snake vertebral articulations provide a seemingly clear example in which structure narrowly constrains function. Even qualitative mechanical analyses clearly indicate that the opposing zygapophyses and zygosphenezygantrum articulations limit the range of torsion that can occur at the vertebral joints of snakes. However, assumptions that vertebral torsion is "wholly impossible" (M osauer, '32), minimal (Gans, "74), or "negligible" (Cundall, '87) are very specific functional inferences that neglect to consider factors that may mediate the apparent mechanical constraints on vertebral torsion. As noted above, oblique muscle insertions may contribute to torsional movements, and even small amounts of torsion per joint are additive over many vertebrae. Therefore, even apparently obvious cases in which function appears to be narrowly constrained by structure must betested empirically.

\section{CONCLUSIONS}

Many published observations of axial twisting movements in snakes indicate a capacity for vertebral torsion. The gopher snakes exami ned here clearly have the muscular and mechanical capacity for vertebral torsion and exhibit vertebral torsion in some natural behaviors. Furthermore, variation in the capacity for torsion along the trunk appears to parallel variation in vertebral morphology. Although more direct measurements of torsion are needed to determinethe amount of twisting that snakes undergo during natural behaviors, the current experimental results refute the hypotheses that vertebral torsion is impossible or negligible in snakes. Vertebral torsion is restricted by the compound articulations, but it does occur in a variety of natural behaviors and can be substantial when added over the many vertebrae involved in snake movements. These results highlight the importance of empirically testing functional inferences de rived sol ely from structural analyses.

\section{ACKNOWLEDGMENTS}

I thank E.D. Brodie III, Margaret Fusari, Captain George Good, Rob Raguso, Cecil Schwal be, and Tom Tayl or for help in obtaining the snakes used in this study. I received very helpful comments on early drafts of the manuscript from Carl Gans, Nate Kley, the reviewers of the 1998 Herpetologists' League Award for Graduate Research (R. Brooks, Linda Ford, David Green, J oseph Mitchell), and two anonymous reviewers. J eroen J eneson kindly helped translate one of the references. Equipment and support were generously provided by Carl Gans, the Rackham Graduate School, and Department of Biology of The University of Michigan. Greg Schneider allowed me to use skeletons UMMZ 183807 and U M MZ 219027 and Steve Hinshaw prepared two additional skeletons.

\section{LITERATURE CITED}

Cundall D. 1987. Functional morphology. In: Seigel RA Collins J T, Novak SS, editors. Snakes: ecology and evolutionary biology. New York: McGraw-Hill. p 106-140.

Dudley R, Gans C. 1991. A critique of symmorphosis and optimality models in physiology. Physiol Zool 64:627637.

Edwards J L. 1985. Terrestrial Iocomotion without appendages. In: Hildebrand M, Bramble DM, Liem KF, Wake DB, editors. Functional vertebrate morphology. Cambridge: Belknap Press. p 159-172.

Fitch HS. 1963. Natural history of the racer Coluber constrictor. Univ Kansas Publ Mus Nat Hist 15:351468.

Frazzetta TH. 1966. Studies on the morphology and function of the skull in the Boidae (Serpentes). II. Morphology and function of the jaw apparatus in Python sebaeand Python molurus. J Morphol 118:217296.

Frolich LM, Biewener AA. 1992. Kinematic and electromyographic analysis of the functional role of the body axis during terrestrial and aquatic locomotion in the salamander Ambystoma tigrinum. J Exp Biol 162:107130.

Gans C. 1974. Biomechanics: an approach to vertebrate biology. New York: Lippincott. 261 p.

Gans C, Gasc] -P. 1992. Functional morphology: require ments and uses. Ann Sci Nat, Zool Biol Anim 13:83-96.

Gans C, Mendelssohn H. 1972. Sidewinding and jumping progression of vipers. In: de Vries A, Kochva $E$, editors. Toxins of animal and plant origin. London: Gordon and Breach. p 17-38.

Garland T, Huey RB. 1987. Testing symmorphosis: does structure match functional requirements? Evolution 41:1404-1409.

Gasc J -P. 1974. L'interprétation fonctionnelle de l'appareil musculo-squel ettique de l'axe vertébral chez les Serpents (Reptilia). Mém Mus N at Hist Nat (Paris) Ser A 83:1-182.

GascJ -P. 1976. Snakevertebrae-a mechanism or merely a taxonomist's toy? In: Bellairs Ad'A, Cox CB, editors. Morphology and biology of reptiles. Linn Soc Symp Ser Vol 3. p 177-190. 
Gasc J -P. 1981. Axial musculature. In: Gans C, Parsons TS, editors. Biology of the Reptilia, vol. 11. New York: Academic Press. p 355-435.

Gasc J -P, Cattaert D, Chasserat C, Clarac F. 1989. Propulsive action of a snake pushing against a single site: its combined analysis. J Morphol 201:315-329.

Greene HW, Burghardt GM. 1978. Behavior and phylogeny: constriction in ancient and modern snakes. Science 200:74-77.

Hoffstetter R, Gasc J -P. 1969. Vertebrae and ribs of modern reptiles. In: Gans C, Parsons TS, Bellairs Ad'A, editors. Biology of the Reptilia, vol. 1. New York: Academic Press. p 201-310.

Hoffstetter R, Gayrard Y. 1965. Observations sur I'osteologie et la classification des Acrochordidae (Serpentes). Bull Mus Nat d'Hist Nat, 2e Serie 36:677696.

Holman J A. 1995. Pleistocene amphibians and reptiles in N orth America. Oxford: Oxford Univ Press. 243 p.

J anoo A, Gasc J -P. 1992. High speed motion analysis of the predatory strike and fluorographic study of oe sophageal deglutition in Vipera ammodytes: more than meets the eye. Amphibia-Reptilia 13:315-325.

J ayne BC. 1982. Comparative morphol ogy of the semispinalis-spinalis muscle of snakes and correlations with locomotion and constriction. J Morphol 172:83-96.

J ayne BC. 1988a. Muscular mechanisms of snake locomotion: an electromyographic study of lateral undulation of the Florida banded water snake (Nerodia fasciata) and the yellow rat snake (Elaphy obsoleta). J Morphol 197:159-181.

J ayne BC. 1988b. The mechanical behavior of snake skin. J Zool (Lond) 214:125-140.

J ohnson RG. 1955. Theadaptiveand phylogenetic significance of vertebral form in snakes. Evolution 9:367388.

Kingsolver J G, Koehl MAR. 1985. Aerodynamics, thermoregulation, and the evolution of insect wings: differential scaling and evolutionary change. Evolution 39: 488-504.

LaDukeTC. 1991. The fossil snakes of Pit 91, Rancho La Brea, California. Contrib Sci, Nat Hist Mus Los Angeles Co 424:1-28.

Lauder GV. 1995. On the inference of function from structure. In: Thomason J J, editor. Functional morphology in vertebrate paleontology. Cambridge: Cambridge Univ Press, $\mathrm{p} 1-18$.

Lauder GV, Shaffer HB. 1988. Ontogeny of functional design in tiger salamanders (Ambystoma tigrinum): Are motor patterns conserved during major morphological transformations?] Morphol 197:249-268.

Lissmann HW. 1949. Rectilinear locomotion in a snake (Boa occidentalis). J Exp Biol 26:368-379.

Moon BR. 1998. Structural and functional integration of the snake axial system. Ph.D. thesis. Ann Arbor: Univ Michigan.

Moon BR, Gans C. 1998. Kinematics, muscular activity, and propulsion in gopher snakes. J Exp Biol 201:26692684.
Mosauer W. 1932. On the locomotion of snakes. Science 76:583-585.

Nishikawa KC, Gans C. 1996. Mechanisms of tongue protraction and narial closure in the marine toad Bufo marinus. J Exp Biol 199:2511-2529.

Nishikawa KC, Anderson CW, Deban SM, O'Reilly J C. 1992. The evolution of neural circuits controlling feeding behavior in frogs. Brain Behav Evol 40:125-140.

Platt DR. 1969. Natural history of the hognose snakes Heterodon platyrhinos and Heterodon nasicus. Univ Kansas Publ Mus Nat Hist 18:253-420.

Pregill GK. 1977. Axial myology of the racer Coluber constrictor with emphasis on the neck region. Trans San Diego Soc Nat Hist 18:185-206.

Rage J -C. 1984. Serpentes. Part 11. In: Wellnhofer P editor. Encyclopedia of paleoherpetology. Stuttgart: Gustav Fischer Verlag.

Rage J -C, Albino AM. 1989. Dinilysia patagonica (Reptilia, Serpentes): matériel vertébral additionnel du Crétacé supérieur d'Argentine. Etude complémentaire des vertébres, variations intraspécifique et intracolumnaires. Neues J ahrb Geolog Paläontol Monatshefte 1989:433-447.

Reilly SM, Lauder GV. 1989. Kinetics of tongue projection in Ambystoma tigrinum: quantitative kinematics, muscle function, and evolutionary hypotheses. J Morphol 199:223-243.

Romer AS. 1956. Osteology of the reptiles. Chicago: Univ Chicago Press. $772 \mathrm{p}$.

Rossman DA, Myer PA. 1990. Behavioral and morphological adaptations for snail extraction in North American brown snakes (genus Storeria). J Herpetol 24:434438

Ruben J A. 1977. Morphological correlates of predatory modes in the coachwhip (Masticophis flagellum) and rosy boa (Lichanura roseofusca). Herpetologica 33: $1-6$

Rudwick MJ S. 1964. The inference of function from structure in fossils. Br J Philos Sci 15:27-40.

Russell ES. 1916. Form and function: a contribution to the history of animal morphology. London: J ohn Murray. $383 \mathrm{p}$.

Sanford CPJ , Lauder GV. 1989. Functional morphology of the "tongue bite" in the osteogl ossomorph fish Notopterus. J Morphol 202:379-408.

Sazima I. 1989. Feeding behavior in the snail-eating snake, Dipsas indica. J Herpetol 23:464-468.

Shine R. 1991. Australian snakes: a natural history. I thaca, NY: Cornell Univ Press. 223 p.

Thomason J , Russell AP. 1986. Mechanical factors in the evolution of the mammalian secondary palate: a theoretical analysis. J Morphol 189:199-213.

Wainwright SA, Biggs WD, Currey J D, Gosline J M . 1976. Mechanical design in organisms. Princeton, $\mathrm{NJ}$ : Princeton Univ Press.

Weishampel DB. 1993. Beams and machines: modeling approaches to analysis of skull form and function. In: Hanken J , Hall BK, editors. The vertebrate skull, vol. 3. Chicago: Univ Chicago Press. p 303-344. 